\title{
Responsabilidade ética e civil do médico-veterinário
} no ambiente hospitalar

\section{Ethical and civil responsibility of veterinary physicians in the veterinary hospital environment}

\section{Resumo}

A importância atribuída pela sociedade aos animais de estimação vem crescendo a cada dia, pois muitas vezes eles são considerados como membros da família. Somando-se a isso o acesso cada vez mais fácil às informações disponibilizadas pelas diversas mídias sociais, o médico-veterinário vem sendo obrigado a aumentar a sua atenção sobre suas responsabilidades éticas e civis, de modo a realizar seu trabalho corretamente e proteger-se de problemas judiciais. Para garantir essa proteção, é fundamental que o profissional siga os Códigos de Ética do Médico-Veterinário, o de Defesa do Consumidor e o Civil, buscando constantemente atualizações na legislação de sua área de trabalho. A obrigação do médico-veterinário no ambiente clínico-hospitalar é considerada de meio, ou seja, ele é obrigado a empenhar todos os esforços possíveis para a prestação de determinado serviço, mas não necessariamente garantir a obtenção de um resultado específico, já que a Medicina não é uma ciência exata. Mas se for constatada a culpa do profissional, negligência, imperícia ou omissão, ele terá que responder a princípio no âmbito administrativo, ou até no jurídico. Este artigo apresenta uma visão geral dos cuidados éticos e civis, dando ênfase a alguns pontos básicos que fazem parte do cotidiano dos profissionais médicos-veterinários que militam no ambiente clínico hospitalar, para que possam ser reduzidas as demandas administrativas e, consequentemente, as judiciais.

\section{Abstract}

The importance given by society to pets has highly increased over the last years, and now it is common to see these animals being considered as part of the family. Additionally, social networks and media in general have facilitated access to information, so veterinarians need to be aware of their ethical and civil responsibilities in order to work according to proper procedures and consequently, avoid legal problems. To guarantee this protection, it is fundamental for veterinarians to be informed about professional and general laws that apply to this subject, by continuously maintaining themselves updated regarding regulations. The obligation of the veterinarian at the veterinary hospital is considered environmental, which means that he/she must put all the necessary efforts into providing the services, but will not necessarily guarantee the achievement of a specific result, since Medicine is not an exact science. However, if there is blame, negligence, misconduct, or omission, the professional will have to answer administratively or even legally. This article has the aim to show a general view of the ethical and civil concerns of veterinarians, emphasizing some primary aspects from the clinical routine of veterinary physicians in the hospital environment in order to reduce administrative, and consequently, judicial demands. 
Ketlen Slowinski ${ }^{1}$

Tália Missen Tremori ${ }^{*}$

Mara Rita Rodrigues Massad ${ }^{3 *}$

Ana Cristina Tasaka ${ }^{4 *}$

Noeme Sousa Rocha ${ }^{5 *}$

\section{Palavras-chave}

Ética. Legislação. Consumidor.

\section{Keywords}

Ethics. Legislation. Consumer.

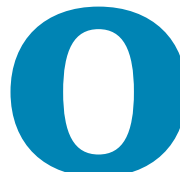

crescimento da importância dada pela sociedade aos animais e aos seus direitos vem aumentando nos últimos tempos e consequentemente os assuntos que envolvem a Medicina Legal Veterinária vêm ganhando destaque. Levando em conta que muitos proprietários consideram seus animais como membros da família, faz-se necessário uma análise da responsabilização dos profissionais de Medicina Veterinária quando causam algum dano ao paciente. Essa intensificação da relação entre seres humanos e animais resultou em um aumento da busca do Poder Judiciário como forma de punir o profissional que cometeu infrações (PAZÓ; HEANCIO, 2014).

Para sua proteção, o profissional deve conhecer a legislação, acompanhar as suas modificações e cumprir as determinações dos órgãos competentes, como o Código de Ética do Médico-Veterinário e o Código de Defesa do Consumidor (PASQUALIN, 2011).

Todo veterinário tem por obrigação ética seguir as normas do Conselho de Medicina Veterinária e o Código de Ética da profissão, que abordam todas as áreas da Medicina Veterinária e fornecem um suporte de grande relevância para o profissional se proteger de problemas civis e judiciais.

1 Médica-veterinária formada pela FMVZ, Unesp, Botucatu. ketlen.slow@gmail.com. Endereço: Depto. de Clínica Veterinária, FMVZ, Distrito de Rubião Junior, s/n., CEP: 18618-970 - Botucatu - SP

2 Médica-veterinária formada pela FMVZ, Unesp, Botucatu, com mestrado em Patologia Animal pela FMVZ, Unesp, Botucatu. Doutoranda aluna da FMVZ, Unesp, Botucatu. talia_missen@hotmail.com.

3 Médica-veterinária formada pela FMVZ, USP, com mestrado em Ciências pela FMUSP, São Paulo, especialização em Medicina Veterinária Legal pela IPRABEC. Doutoranda aluna da FMVZ, Unesp, Botucatu. maramassad@gmail.com.br.

4 Médica-veterinária formada pela FMVZ, USP, com mestrado e doutorado em Patologia Experimental e Comparada pela Universidade de São Paulo. Professora da Universidade Paulista, UNIP. actasaka@ig.com.br.

5 Médica-veterinária formada pela Universidade Estadual do Maranhão - UEMA, Residência em Patologia Veterinária pela FMVZ, Unesp, Botucatu, com mestrado e doutorado em Patologia pela FMB, Unesp, Botucatu. Professora Adjunta no Depto. de Clínica Veterinária, Livre Docente, FMVZ, Unesp, Botucatu. rochanoeme@fmvz. unesp.br.

*Membro da Comissão Técnica de Medicina Veterinária Legal do CRMV-SP. 
De acordo com a Lei $n^{\circ} 10.406$ (BRASIL, 2002) do Código Civil Brasileiro, "entende-se por responsabilidade civil o dever que incumbe a qualquer cidadão de reparar o prejuízo causado a alguém", e as profissões da área da saúde são consideradas de risco, tanto para quem exerce como para quem recebe (PASQUALIN, 2011).

A prestação de serviços do médico-veterinário é considerada relação de consumo (PAZÓ; HEANCIO, 2014) e, nesse caso, o responsável pelo animal tem o papel de consumidor. O Código de Defesa do Consumidor define como consumidor, de acordo com a Lei no 8078/90, "toda pessoa física ou jurídica que adquire ou utiliza produto ou serviço como destinatário final" (BRASIL, 1990).

De acordo com o art. $6^{\circ}$ do Código de Defesa do Consumidor, são direitos básicos do consumidor: a proteção da vida, saúde e segurança contra riscos provocados por práticas no fornecimento de produtos e serviços considerados perigosos ou nocivos, a informação adequada e clara sobre os diferentes produtos e serviços, com especificação correta de quantidade, características, composição, qualidade e preço, bem como sobre os riscos que apresentem.

No art. 24, capítulo IX, do Código de Ética do Profissional Veterinário consta a necessidade do conhecimento das normas que regulamentam a sua atividade, oferecer produtos e serviços que indiquem o grau de nocividade, evitando, assim, dano à saúde animal e humana, ao meio ambiente e à segurança do cidadão (CFMV, 2007). Os artigos destacados mostram que o médico-veterinário deve ter conhecimento do seu papel como cidadão, profissional e prestador de serviço, tomando sempre o cuidado de explicar a situação do paciente, os procedimentos que deverão ser realizados, os riscos e esclarecer todas as dúvidas com clareza, evitando a ocorrência de problemas futuros com o cliente por falta de informação ou por interpretação errada.

A obrigação do médico-veterinário no ambiente clínico hospitalar é considerada de meio, ou seja, ele é obrigado a empenhar todos os esforços possíveis para a prestação de determinado serviço, e está previsto no Art. $1^{\circ}$ do Código de Ética que o médico-veterinário "deve exercer a profissão com o máximo de zelo e o melhor de sua capacidade" (CFMV, 2007). Mas esse profissional não necessariamente tem que garantir a obtenção de um resultado específico (PASQUALIN, 2011), já que a Medicina não é uma ciência exata. Porém, se for constatada uma falha do profissional, ele terá que responder no âmbito ético, civil ou até mesmo jurídico.

O presente trabalho desenvolve uma visão geral dos cuidados éticos e civis, dando ênfase a alguns pontos básicos que fazem parte do cotidiano dos profissionais médicos-veterinários no ambiente clínico hospitalar, os quais muitas vezes têm sido negligenciados, gerando demandas judiciais desnecessárias.

\section{Revisão de literatura}

Desde a promulgação do Código de Defesa do Consumidor, a prestação de serviço pelo médico-veterinário é considerada uma relação de consumo com o responsável pelo paciente (PASQUALIN, 2011). Portanto, pelos preceitos legais mencionados, uma falha no atendimento deve ser atribuída a um responsável, o qual tem o dever de reparar o prejuízo causado.

De acordo com Pasqualin (2011), "a prestação de serviço se inicia a partir do contato do cliente com o consultório, clínica ou hospital, o que pode ser viabilizado por telefone ou pessoalmente, mas a responsabilidade já existe no momento da informação publicitária".

É de grande importância que o médico-veterinário atente para o Código de Defesa do Consumidor, pois nele estão descritas as normas cabíveis a sua rotina de trabalho.

Propaganda: como citado nos arts. 32, 33 e 34 do Código de Ética do Médico-Veterinário, a propaganda deve ser verídica e exposta de maneira clara para que o cliente não tenha uma interpretação errônea (CFMV, 2007). Reforçado ainda pelo art. $6^{\circ}$ do Código de Defesa do Consumidor, o qual onde descreve que "a proteção contra publicidade enganosa e abusiva, métodos comerciais desleais, bem como contra práticas e cláusulas abusivas ou impostas no fornecimento de produtos e serviços" é um direito básico do consumidor. É fundamental sempre lembrar que a prestação do serviço se inicia a partir do contato do cliente com o médico-veterinário, independentemente do meio de comunicação utilizado, ou seja, a responsabilidade já existe no momento da informação publicitária (PASQUALIN, 2011).

Custos dos serviços: devem seguir um padrão. $\mathrm{O}$ art. 21 do Código de Ética de Médico-Veterinário não permite concorrência desleal entre os profissionais (CFMV, 2007).

Informação ao cliente: o profissional deve explicar o procedimento que será realizado, informando os riscos, o grau de necessidade, o material a ser utilizado, deixando claro que a Medicina Veterinária não é uma ciência exata e que os resultados também não são, além de informar sobre todas as opções adequadas, permitindo que o cliente faça a sua escolha.

Registro: obter todas as informações do paciente e dos procedimentos realizados, anotados no Termo de Consentimento Livre e Esclarecido, onde deve constar a assinatura do responsável legal pelo animal, certificando-se de que ele está ciente, inclusive dos riscos, e que concorda com o procedimento a ser realizado. 
Nunca esquecer que o proprietário, no papel de consumidor, tem o direito de escolha e liberdade na contratação de um serviço. Por isso, ele pode optar pela não realização do procedimento, devendo, então, assinar um documento informando que tem ciência de que o procedimento é necessário, mas que não concordou com a sua realização.

Devido à relação de prestação de serviço estabelecida entre o profissional e o proprietário, é importante ter sempre disponível o Código de Defesa do Consumidor para consulta no caso de surgimento de dúvidas tanto do cliente quanto do profissional.

De acordo com o art. 34 do Código de Defesa do Consumidor, Lei $\mathrm{n}^{\circ} 8.078$, “o fornecedor do produto ou serviço é solidariamente responsável pelos atos de seus representantes", ou seja, o médico-veterinário responsável pela clínica ou hospital responde pelos atos de todos os funcionários do local (BRASIL, 1990).

As penalidades referentes às infrações das normas de defesa do consumidor estão descritas no art. 56 do Código de Defesa do Consumidor. Essas penalidades, chamadas de sanções administrativas, variam de acordo com o caso, podendo ser "multa, suspensão de fornecimento de produtos ou serviços, suspensão temporária de atividade, revogação de concessão ou permissão de uso, cassação de licença do estabelecimento ou de atividade, intervenção administrativa, imposição de contra propaganda", todas previstias na Lei no 8.078 (BRASIL, 1990).

\section{Prontuário}

Conforme França (2002), “entende-se por prontuário médico não apenas o registro do paciente, mas todo o acervo documental padronizado, organizado e conciso referente ao registro dos cuidados médicos prestados, assim como aos documentos pertinentes a essa assistência”. Esse documento consta de exame clínico do paciente, suas fichas de ocorrências e de prescrição terapêutica, os relatórios de enfermagem, anestesia, cirurgia, resultados de exames complementares e até mesmo a solicitação destes.

Os prontuários constituem um verdadeiro dossiê que tanto serve para análise da evolução da doença, para fins estatísticos, que alimenta a memória do serviço, como para defesa do profissional, caso ele venha a ser responsabilizado por algum resultado atípico ou indesejado. Apesar de o autor se referir à Medicina Humana, o trecho cabe perfeitamente à Medicina Veterinária. Por isso, o prontuário não deve ser utilizado apenas como um controle, por exemplo, para ajudar na contratação de cobranças.

É imprescindível que o prontuário esteja sempre completo e atualizado. No caso de litígio judicial, a ficha clínica é, provavelmente, o documento mais importante, e muitas vezes o único que pode comprovar o estado inicial do paciente. Nele devem ser incluídos a identificação completa do paciente, como nome, espécie, raça, porte, sexo, idade, pelagem, além da identificação e dados do responsável, incluindo telefone e endereço para garantir o contato caso seja necessário. A ficha clínica também deve conter a queixa principal relatada, anamnese, o histórico de saúde do animal, que pode indicar limitações e cuidados durante a terapia, e o responsável pelo paciente deve fornecer informações idôneas e corretas. Ainda deve conter os sinais clínicos, manifestações verificadas no exame físico inicial pelo médico-veterinário, as quais devem ser descritas em detalhes. Sugere-se que o cliente assine a ficha clinica impressa para sustentar a idoneidade das informações cedidas (PAZÓ; HEANCIO, 2014).

Outra questão importante é que muitos acham que o prontuário pertence ao profissional, mas é de propriedade do responsável pelo animal. Porém, de acordo com França (2002), "não existe nenhum dispositivo ético ou jurídico que determine ao profissional que ele deva entregar o documento original". Caso o proprietário solicite, o médico-veterinário pode entregar uma cópia do documento.

\section{Publicidade e propaganda}

Todas as informações publicitárias devem ser claras e precisas, não enganosas ou abusivas. A Resolução $\mathrm{n}^{\circ}$ 780/2004 do Conselho Federal de Medicina Veterinária é a legislação de regência sobre a publicidade, que é considerada a divulgação pública, veiculada por qualquer forma ou meio de comunicação, de atividade profissional resultante de iniciativa, participação e/ou anuência do médico-veterinário (PASQUALIN, 2011).vÉ proibido realizar consulta, diagnóstico ou prescrição de tratamento por meio de veículos de comunicação de massa ou expor a imagem de paciente seu como meio de difundir um procedimento médico-veterinário ou o resultado de um tratamento, sem autorização prévia do responsável pelo animal (CFMV, 2007; PASQUALIN, 2011).

A propaganda pessoal, os receituários e a divulgação de serviços profissionais devem ser produzidos em termos discretos. As placas indicativas de estabelecimentos médicos-veterinários, os anúncios e impressos devem conter dizeres compatíveis com os princípios éticos, não implicando autopromoção, restringindo-se ao nome do profissional, profissão e número de inscrição no CRMV, especialidades comprovadas, título de formação acadêmica mais relevante, endereço, telefone, horário de trabalho e serviços oferecidos. Seguindo essas normas, o profissional evita problemas para si e para o próprio estabelecimento (CFMV, 2007; PASQUALIN, 2011). 


\section{Eutanásia}

A eutanásia é a morte provocada de maneira humanitária, sob a responsabilidade de um médico-veterinário, de acordo com a Resolução n 714 do Conselho Federal de Medicina Veterinária de 20 de junho de 2002. Ela nunca deve ser realizada sem a autorização, por escrito, do cliente ou agente legal. Médicos-veterinários têm sido processados por clientes que negaram ter dado permissão verbal para a eutanásia de seus animais (MENEZES et al., 2005).

A associação de técnicas de anestesia geral com a administração de cloreto de potássio é um método eficiente e que proporciona uma morte sem sofrimento, provocando perda da consciência e cessação dos batimentos cardíacos (MENEZES et al., 2005).

A eutanásia não é apenas uma vontade do proprietário, mas sim uma escolha oferecida e justificada pelo médico-veterinário. A decisão deve ser baseada em critérios como: diagnóstico, estado geral, qualidade de vida do animal, insucesso nos tratamentos existentes, prognóstico, risco à saúde pública. O Conselho de Ética de Medicina Veterinária deixa claro que a eutanásia deve ser feita em casos devidamente justificados (CFMV, 2007).

De acordo com o DECRETO $n^{\circ} 24.645$, mais precisamente no art. $3^{\circ}$, caracteriza-se como maus-tratos não oferecer morte rápida, livre de sofrimento prolongado, a qualquer animal cuja eutanásia seja necessária, podendo o médico-veterinário responder judicialmente se ela não for efetuada de forma correta (BRASIL, 1934).

\section{Doenças de Notificação Compulsória}

A luta contra as zoonoses constitui uma da s principais atividades da saúde pública veterinária. A prevenção e a eliminação desse tipo de enfermidade no homem dependem, em grande parte, das medidas adotadas contra essas doenças em animais (PFUETZENREITER; ZYLBERSZTAJN; PIRES, 2004).

Pelo menos metade dos 1.170 agentes conhecidos que infectam seres humanos tem um vertebrado ou inseto como reservatório, e muitas doenças emergentes são zoonoses (PFUETZENREITER; ZYLBERSZTAJN; PIRES, 2004).

De acordo com o art. $8^{\circ}$ da Lei no 6.259 , “é dever de todo cidadão comunicar à autoridade sanitária local a ocorrência de fato comprovado ou presumível de caso de doença transmissível, sendo obrigatória a médicos e outros profissionais de saúde no exercício da profissão, bem como aos responsáveis por organizações, estabelecimentos públicos e particulares de saúde e ensino, a notificação de casos suspeitos ou confirmados das doenças de notificação compulsória" (BRASIL, 1975).

Sempre que o médico-veterinário suspeitar de uma doença que se enquadre na lei citada anteriormente, deve entrar em contato com o órgão de responsabilidade pública, que nesse caso é o Ministério da Agricultura, Pecuária e Abastecimento (MAPA). As doenças pertinentes a esse grupo podem ser encontradas no site do governo: www.agricultura.gov.br.

\section{Conduta sobre animais comercializados ilegalmente}

Compra, venda e captura de animais silvestres é crime previsto na Lei Federal no 9.605 (BRASIL, 1998).

Atualmente, é comum a procura por atendimento veterinário para animais silvestres, provocando dúvidas ao profissional de como agir nessa situação. Existem lojas que comercializam animais silvestres nascidos em cativeiro, o qual, de acordo com Antunes (2004), "é previsto em Lei Federal (Portaria 118 N/MMA-IBAMA de 15/10/1997), que foi criada como uma forma de estimular a reprodução dos animais mais procurados em criadouros regulamentados e fiscalizados, para que atendessem às demandas do comércio, desvalorizando ações do tráfico". Mas quando o certificado do IBAMA não existe, o animal é de origem ilegal, gerando a dúvida no médico-veterinário de como proceder.

De acordo com a UNESCO (1978), "todos são iguais perante a vida e têm os mesmos direitos de existência e todos os animais têm o direito à atenção, cuidados e proteção do homem".

$\mathrm{O}$ atendimento clínico-cirúrgico de animais silvestres, mesmo que ilegais, não se caracteriza como crime ambiental ou infração administrativa previstos na Lei $\mathrm{n}^{\circ} 9.605$ (BRASIL, 1998). Além disso, a Resolução nº 829 do CFMV (2006) diz que "os animais silvestres/selvagens devem receber assistência médico-veterinária independente de sua origem". Então, o coerente é não negar atendimento ao animal, informar ao proprietário que comprar um animal ilegal é crime previsto em lei, portar animais sem a autorização do IBAMA também é caracterizado como crime e que o médico-veterinário, como profissional da saúde, tem obrigação de comunicar o fato aos órgãos competentes.

$\mathrm{O}$ atendimento deve ocorrer normalmente de acordo com a rotina do estabelecimento, preenchendo o formulário completo do paciente, não se esquecendo de anotar os dados do proprietário (ABRAVAS, 2010). Para garantir que informou o cliente sobre a lei, é interessante fazer com que ele assine um termo de ciência sobre o assunto e a lei. De acordo com o Código de Ética do Médico-veterinário - CFMV (2007), "é de competência do profissional veterinário o exercício de atividades ou funções públicas e particulares, entre elas, a defesa da fauna, e especialmente o controle da exploração das espécies animais silvestres, bem como seus produtos". 


\section{Erro médico}

Um erro médico pode levar o médico-veterinário a uma condenação pelo Conselho de Medicina Veterinária ou até mesmo pela Justiça. Claro que o conceito de erro não é algo fácil quando se trata de uma área biológica como a Medicina Veterinária, pois não é uma ciência exata (PASQUALIN, 2011).

No caso de um possível erro técnico, o papel do juiz é o de analisar se o médico-veterinário teve culpa no modo pelo qual procedeu ao diagnóstico, se recorreu, ou não, a todos os meios a seu alcance, desde as preliminares com o paciente até os exames laboratoriais, bem como se foram aplicados os remédios e tratamentos indicados pela ciência e pela prática (ABATE, 2006).

O questionamento sobre um possível erro técnico não é mais incomum na rotina do médico-veterinário, pois os animais estão sendo cada vez mais humanizados, e as pessoas cada vez mais conscientes dos seus direitos legais. Por isso mais uma vez deve-se ressaltar a importância de se registrar tudo na ficha do paciente e esclarecer de forma clara e objetiva todas as questões para o proprietário, que nesse caso é o consumidor, mas muitos consideram os seus animais como membros da família, tornando a situação ainda mais crítica caso o profissional tenha cometido um erro.

Judicialmente existem classificações para os erros médicos; de acordo com Abate (2006), define-se como "erro culposo os casos em que o médico, no exercício de sua profissão, prejudicou o seu paciente, o qual deveria antes beneficiar, mas sem intenção não foi atingido o resultado esperado".

Negligência é quando o médico não fez o que deveria fazer; define-se como a falta de observância aos deveres e cuidados que a situação demanda. Imprudência se caracteriza quando o profissional é capacitado para executar o procedimento, mas o realiza de forma irresponsável, sem precaução, precipitadamente. Imperícia é caracterizada quando há um despreparo do profissional para a realização do procedimento realizado, falta de conhecimento técnico, que resulta em dano ao paciente (ABATE, 2006).

O dono do animal é um consumidor e também o fornecedor de serviço; no caso o médico-veterinário, como previsto no Código de Defesa do Consumidor - Lei ${ }^{\circ}$ 8.078, "responde, independentemente da existência de culpa, pela reparação dos danos causados aos consumidores por defeitos relativos à prestação dos serviços, bem como por informações insuficientes ou inadequadas sobre fruição e riscos" (BRASIL, 1990). O diálogo com o cliente é essencial para evitar problemas. É necessário que o médico-veterinário explique tudo sobre o diagnóstico, prognóstico, esclarecendo todas as possibilidades de tratamento e as vantagens e desvantagens de cada um. É importante responder a todas as dúvidas do proprietário de forma clara, de modo que não permaneça qualquer ponto obscuro, para que o cliente não interprete como erro a obtenção de um resultado inesperado por falta de informação do médico-veterinário. Claro que se o dano ocorreu por culpa do próprio consumidor, o médico-veterinário não será responsabilizado.

\section{Receituários e atestados}

Dentro do cotidiano do profissional médico-veterinário, é comum proprietários solicitarem informações via telefone, ou então pedir receitas de medicamentos para consumo próprio e não para o animal. Essas práticas são ilegais e são caracterizadas como crime de falsidade ideológica, previsto na Lei $\mathrm{n}^{\circ} 2.848$, representado por "omitir, em documento público ou particular, uma declaração que dele devia constar, ou nele inserir ou fazer inserir declaração falsa ou diversa da que devia ser escrita, com fim de prejudicar direito, criar obrigação ou alterar a verdade sobre fato juridicamente relevante" (BRASIL, 1940).

Essa Lei cabe àquelas situações em que o médico-veterinário disponibiliza um atestado de saúde, garantindo que o animal está apto a viajar, sem realizar o exame clínico e verificar se o seu protocolo de vacinas está em dia. A pena para o crime de falsidade ideológica é: reclusão, de um a cinco anos, e multa, se o documento é público, e reclusão de um a três anos, e multa, se o documento é particular.

Outra situação que o médico-veterinário deve ficar atento é a relacionada aos receituários. No art. 13 do capítulo IV do Código de Ética (CFMV, 2007) consta que "é vedado ao veterinário receitar ou atestar de forma ilegível ou assinar sem preenchimento prévio do receituário, laudos, atestados, certificados e outros".

Os receituários devem seguir um padrão para evitar a ocorrência de um erro de interpretação, tanto por falta de informação como ao não entendimento causado por estar ilegível. A prescrição exerce papel fundamental no tratamento medicamentoso, por ser um instrumento que contribui para o uso correto de medicamentos. Entende-se que as prescrições incompletas, ilegíveis ou com rasuras impedem a eficiência da interpretação, colocando em risco a qualidade da assistência farmacêutica ao paciente e levando ao comprometimento no tratamento farmacoterapêutico e erros de medicação (MASTROIANNI, 2009).

\section{Conclusão}

O crescimento da importância dada pela sociedade aos animais e aos seus direitos vem aumentando nos últimos tempos e, consequentemente, os assuntos que envolvem a Medicina Veterinária vêm ganhando destaque. 
O médico-veterinário deve estar atento ao Código de Ética do Profissional Veterinário, às Normas do Conselho Regional de Medicina Veterinária e às leis do Código de Defesa do Consumidor e do Código Civil. Desempenhando seu papel com responsabilidade profissional e civil, estará automaticamente se protegendo de possíveis penalidades e culpa.

A obrigação do médico-veterinário no ambiente clínico-hospitalar é considerada de meio, ou seja, ele é obrigado a empenhar todos os esforços possíveis para a prestação de determinado serviço, mas não necessariamente de garantir a obtenção de um resultado específico, pois a medicina não se enquadra em uma ciência exata; porém, se for constatada uma falha do profissional, ele terá de responder no âmbito ético e civil.

\section{Agradecimento}

\section{CAPES (Edital Pró-Forenses 25/2014).}

\section{Referências}

ABATE, A. O erro médico: erro de diagnóstico e erro de procedimento. Informativo Jurídico, n. 35, p. 1-4, 2006. Disponível em: <http://cslaw.com.br/pdf/info_sau35.pdf>. Acesso em: 12 jul. 2013

ABRAVAS. SIMPÓSIO DE MEDICINA E CONSERVAÇÃO DE ANIMAIS SELVAGENS, 2010, Vila Velha. Anais... Vila Velha: ABRAVAS, 2010. Disponível em: <http://www. abravas.org.br/>. Acesso em: 30 set. 2013.

ANTUNES, D. A. A importância do comércio legal frente ao comércio ilegal de animais silvestres. Brasília: [s.n.], 2004.

BRASIL. Decreto n. 24.645, de 10 de julho de 1934. Estabelece medidas de proteção aos animais. Poder Legislativo. Diário Oficial da União, 14 jul. 1934. Suplemento n. 162. Disponível em: <http://louveira.sp.gov.br/site/painel/dbarquivos/dbanexos/ leidemaustratosp.pdf>. Acesso em: 16 mar. 2013.

Lei n. 2.848, de 7 de dezembro de 1940. Diário Oficial da República Federativa do Brasil, Poder Executivo, Brasília, DF, 31 dez. 1940. Seção 1, p. 23911. Disponível em: <http://www2.camara.leg.br/legin/fed/declei/1940-1949/decreto-lei-2848-7dezembro-1940-412868-publicacaooriginal-1-pe.html>. Acesso em: 16 mar. 2013.

Lei n. 6.259, de 30 de outubro de 1975. Dispõe sobre a organização das ações de Vigilância Epidemiológica, sobre o Programa Nacional de Imunizações, estabelece normas relativas à notificação compulsória de doenças, e dá outras providências. Diário Oficial da União, Brasília, DF, 17 jul. 1975. Disponível em: <http://www.planalto.gov.br/ccivil_03/ leis/L6259.htm>. Acesso em: 16 mar. 2013.

Lei n. 8.078/90, de 11 de setembro de 1990. Código de Defesa do Consumidor, Poder Legislativo, 12 set. 1990. cap. 1, p. 1. Disponível em: <http://www.planalto.gov. br/ccivil_03/leis/L8078.htm>. Acesso em: 22 jul. 2013.

Lei n. 9.605, de 12 de fevereiro de 1998. Diário Oficial da União, Poder Legislativo, Brasilia, DF, 13 fev. 1998. Disponível em: <http://www.planalto.gov.br/ccivil_03/leis/ L9605.htm>. Acesso em: 16 mar. 2013.

Lei n. 10.406, de 10 de janeiro de 2002. Código Civil Brasileiro, Poder Legislativo, 11 jan. 2002. Seção 3, Art. 927. Disponível em: <http://www.planalto.gov.br/ccivil_03/ leis/2002/l10406.htm>. Acesso em: 22 jul. 2013. Acesso em: 16 mar.2013.
CFMV - CONSELHO FEDERAL DE MEDICINA VETERINÁRIA. Resolução n. 829, de 25 de abril de 2006. Diário Oficial da União, Brasília, DF, 6 jun. 2006. Seção 1, p. 113. Disponível em: <http://portal.cfmv.gov.br/portal/lei/index/id/236>. Acesso em: 20 abr. 2013

Resolução n. 875, de 12 de dezembro de 2007. Diário Oficial da União, Brasília, DF, 31 dez. 2007. Seção 1, p. 137-139. Disponível em: <http://www.crmvsp.gov.brsite/ cod_etic_med_vete.php>. Acesso em: 16 mar. 2013

FRANÇA, G. V de. Flagrantes médico-legais. Pernambuco: Universitária, 2002. v. 4.

MASTROIANNI, P. C. Análise dos aspectos legais das prescrições de medicamentos. Revista de Ciências Farmacêuticas Básica e Aplicada, Araraquara, SP, v. 30, n. 2, p. 173-176, 2009

MENEZES, D. C. R. et al. Eutanásia em pequenos animais em Teresina-PI. Semina: ciências agrárias, Londrina, v. 26, n. 4, p. 575-580, out./dez. 2005.

PASQUALIN, A. C. Orientações ao médico-veterinário: manual de direitos e deveres. Curitiba: SINDIVET, 2011

PAZÓ, C. G.; HEANCIO, S. F. Responsabilidade civil do médico-veterinário: uma análise à luz do código de ética do médico-veterinário. Espírito Santo: Faculdade de Direito de Vitória, 2014. Disponível em: <http://www.idb-fdul.com/uploaded/files/2014>. Acesso em: 25 jan. 2014.

PFUETZENREITER, M. R.; ZYLBERSZTAJN, A.; PIRES, F. D. A. Evolução histórica da medicina veterinária preventiva e saúde pública. Santa Maria, v. 34, n. 5, p. 1661-1668, set./out. 2004.

UNESCO. Declaração Universal dos Direitos dos Animais. Paris: UNESCO, 1978. 


\section{ERRATA}

Diferentemente do publicado na página 29 do Volume 1 de 2016 da Revista MV\&Z, a autora do Artigo "A necessidade do fortalecimento do conhecimento humanístico na formação do médico-veterinário: a visão de estudantes do segundo semestre de graduação" é Paula Tavolaro, e não Anna Paula Tavolaro.

$\mathrm{O}$ resumo "Evaluation of depressive-like behavior in adults mice associated with administration of subcutaneous injection of ethanol in neonatal period", publicado na página 50 do Volume 1 de 2016 da Revista MV\&Z, não listou os seus autores, que são BERTAGLIA, EVERTON BARBOSA; SPINOSA, HELENICE DE SOUZA ${ }^{1}$. 